\title{
EfFect Of SPINdLe SPEed On TeXTILE Properties AND Productivity Of Fine Jute YARN
}

\author{
${ }^{1}$ Md. Osman Ghani Miazi, ${ }^{2}$ A. K. M. Mahabubuzzaman and ${ }^{3}$ Md. Mazedul Kabir \\ ${ }^{1}$ Mechanical Processing Division \\ ${ }^{2}$ Department of Spinning, Mechanical Processing Division \\ ${ }^{3}$ Mechanical Processing Division \\ Bangladesh Jute Research Institute (BJRI), Manik Mia Avenue, Dhaka-1207, \\ E-mail: miazi_2009@yahoo.com
}

\begin{abstract}
Spindle speed is an important parameter for the production of jute yarn [1]. An Apron Draft spinning frame was modified in to ring system by incorporating rings and travelers instead of flyers. The experiments were performed for investigating the effect of spindle speed on textile properties and productivity of jute yarn of 103 tex. The spindle speed was varied from $5000 \mathrm{rpm}$ to $9000 \mathrm{rpm}$. The experiments were performed with Bangla White $B(B W B)$ grade jute sliver of finisher drawing of linear density 2415 tex (70 lb/spy). The draft ratio and the twist used in the experiments were 23 and 240 tpm (turns per meter) respectively. The ring size was $K W$ (4) $76 \mathrm{~mm} \varnothing$. Steel travelers number 1, Type G, semicircular in shape were used in the experiment. Ten runs were performed for the experiment at the standard atmospheric condition, $20 \pm 2^{\circ} \mathrm{C}$, and relative humidity $65 \% \pm 2 \%$. The nominal count of the yarn produced was 103 tex. The yarns produced through the experiments were tested for different textile properties. Analysis of the test results shows that the spindle speed greatly influences the textile properties, such as strength, elongation, yarn breakage, productivity, quality ratio etc. of produced yarn. In consideration of the productivity, quality and other textile properties of the yarn, the optimum spindle speed was determined for the production of fine jute yarn of 103 tex.
\end{abstract}

Key Words: Apron draft, spindle speed, fine jute yarn.

\section{Introduction}

Apron Draft Flyer type spinning machine is available in many jute mills of Bangladesh and other countries [2]. The machine is used for the production of jute yarn heavier than 170 tex. The machine is shown in Fig. 1. At present jute is facing serious competition from synthetic/man-made fibre. To overcome this situation it is necessary to develop and introduce diversified jute products in the market [3]. Fine jute yarn is essential for making different diversified products of jute [4]. Western Europe has already developed different ring spinning machine [Report, 2000], but these are not cost effective for jute industries. The Apron Draft Flyer spinning machine was modified to ring system by introducing rings and travelers instead of flyers [5]. In addition, some modifications in the delivery zone and in the power transmission mechanism of the machine were made. The modified machine is shown in Fig. 2.

\section{Materials and Method}

Bangla White B (BWB) grade jute fibre was used as raw material. Jute yarn of 103 tex linear density was produced from the finisher drawing sliver of around 2415 tex (70 lb/spy). The back processing for the production of the said input sliver was carried out following the conventional jute back processing system. The spindle speed of the experimental machine was increased up to $9000 \mathrm{rpm}$ from its original speed of 3500 to $4250 \mathrm{rpm}$. Experiments were conducted using 5000 to $9000 \mathrm{rpm}$ spindle speed, and thus different samples of yarns were produced at different spindle speeds. The textile properties of the produced samples were tested through a computerized Universal Testing machine (Instron machine). Produced yarns were weighed through a digital electronic balance for determining the actual linear density of the yarn as well as productivity of the machine.

Spindle speed of the machine varied by changing the motor pulley of the machine. 
Speeds of the spindles were measured with a digital Tachometer. In this experiment, inserted twist of the yarn was $240 \mathrm{tpm}$, KW (4) $76 \mathrm{~mm}$ $\varnothing$ steel ring and type G, No. 1 Travellers were used. The experiments and all tests of yarn were performed in standard textile testing laboratory [6].

\section{Results}

The different properties of 103 tex jute yarn were measured and their values are given in the table. Quality ratio is the main criteria for assessing the quality of a yarn. Result shows that productivity and elongation was increased up to $8000 \mathrm{rpm}$, which seems to have reversed again with further increase of the spindle speed (Fig. 3). Quality ratio decreased with the increase of spindle speed of the machine (Fig. 4). At initial stage the breakage of yarns increased almost linearly with the increase of spindle speed, which showed an abrupt increase of yarn breakage beyond $8000 \mathrm{rpm}$ spindle speed.

Table 1 Textile properties of yarn produced by the modified Apron draft ring spinning machine

\begin{tabular}{|c|c|c|c|c|c|c|c|}
\hline $\begin{array}{c}\text { Spindle } \\
\text { speed } \\
\text { rpm }\end{array}$ & $\begin{array}{c}\text { Load } \\
\text { at } \\
\text { break } \\
\text { kgf }\end{array}$ & $\begin{array}{c}\text { Elongation } \\
\%\end{array}$ & $\begin{array}{c}\text { Tenacity } \\
\text { N/tex }\end{array}$ & $\begin{array}{c}\text { Textile } \\
\text { modulus } \\
\text { N/tex }\end{array}$ & $\begin{array}{c}\text { No. of yarn } \\
\text { breakage/sp } \\
\text {-hr. }\end{array}$ & $\begin{array}{c}\text { Production } \\
\text { rate } \\
\text { g/sp.-hr. }\end{array}$ & $\begin{array}{c}\text { Quality } \\
\text { ratio } \\
\%\end{array}$ \\
\hline 5000 & 1.293 & 1.120 & 0.086 & 6.58 & 0.50 & 109 & 95.1 \\
\hline 5500 & 1.210 & 1.230 & 0.096 & 6.61 & 0.54 & 121 & 88.7 \\
\hline 6000 & 1.150 & 1.397 & 0.096 & 6.85 & 0.62 & 135 & 84.3 \\
\hline 6500 & 1.077 & 1.410 & 0.098 & 6.87 & 0.75 & 157 & 79.7 \\
\hline 7000 & 1.052 & 1.476 & 0.102 & 6.91 & 0.85 & 188 & 77.1 \\
\hline 7500 & 1.020 & 1.520 & 0.116 & 6.12 & 0.90 & 192 & 74.8 \\
\hline 8000 & 1.017 & 1.665 & 0.123 & 7.37 & 1.00 & 208 & 74.7 \\
\hline 8500 & 0.980 & 1.510 & 0.113 & 6.01 & 1.40 & 170 & 71.8 \\
\hline 9000 & 0.960 & 1.430 & 0.095 & 5.93 & 2.20 & 156 & 70.4 \\
\hline
\end{tabular}

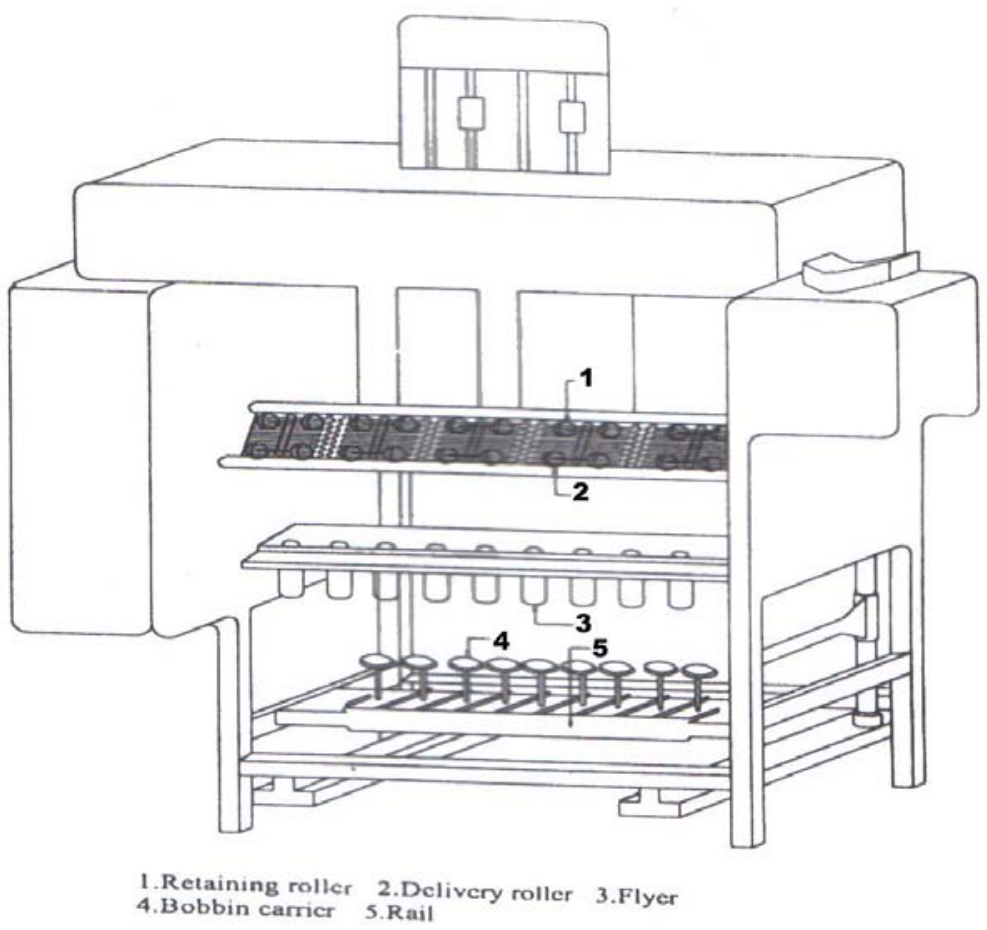

Fig. 1 Existing apron draft flyer spinning machine 


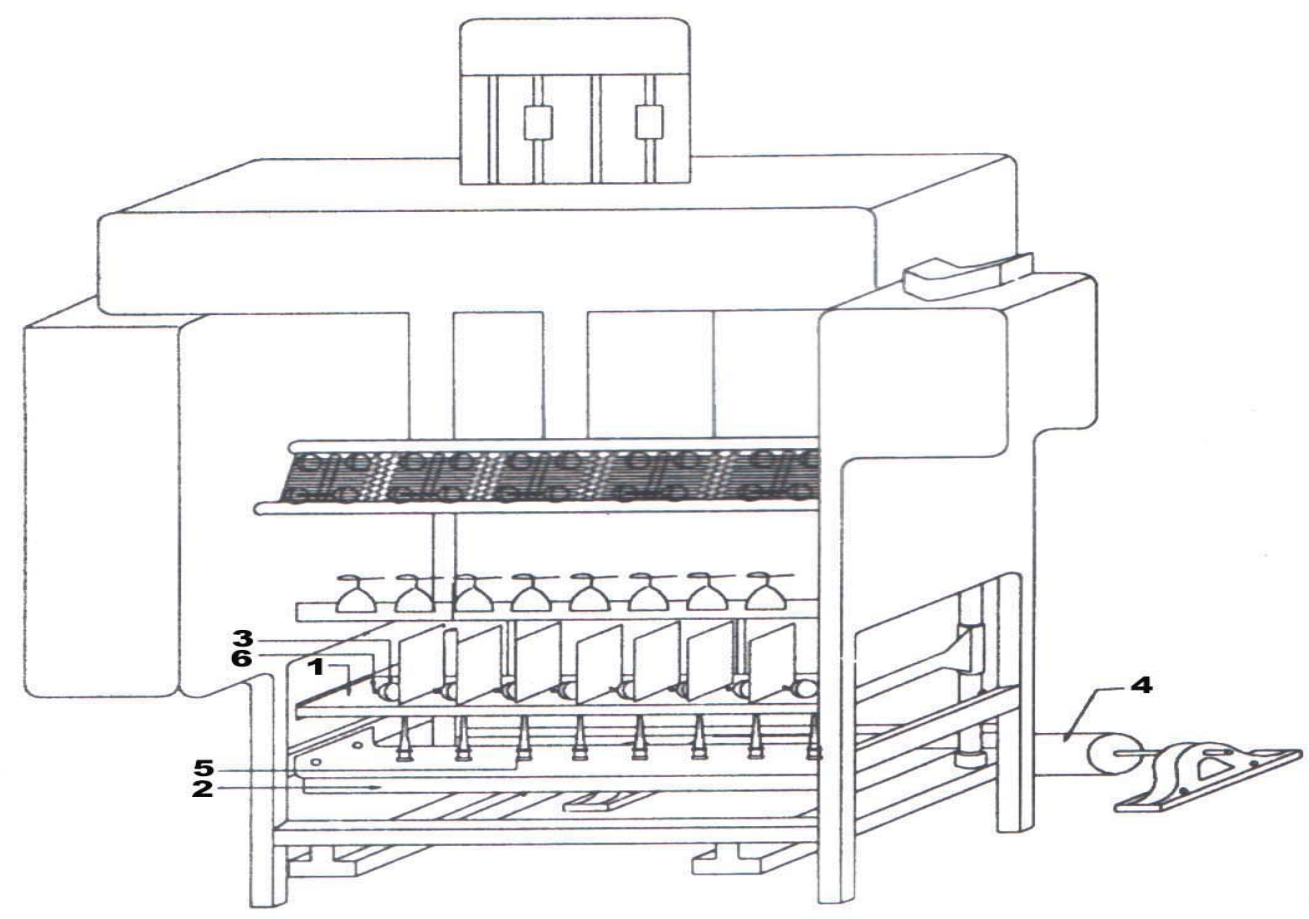

1.Upper rail 2.Lower rail 3.Ring

4.Roller 5.Spindle 6.Traveller

Fig. 2 Modified ring spinning machine

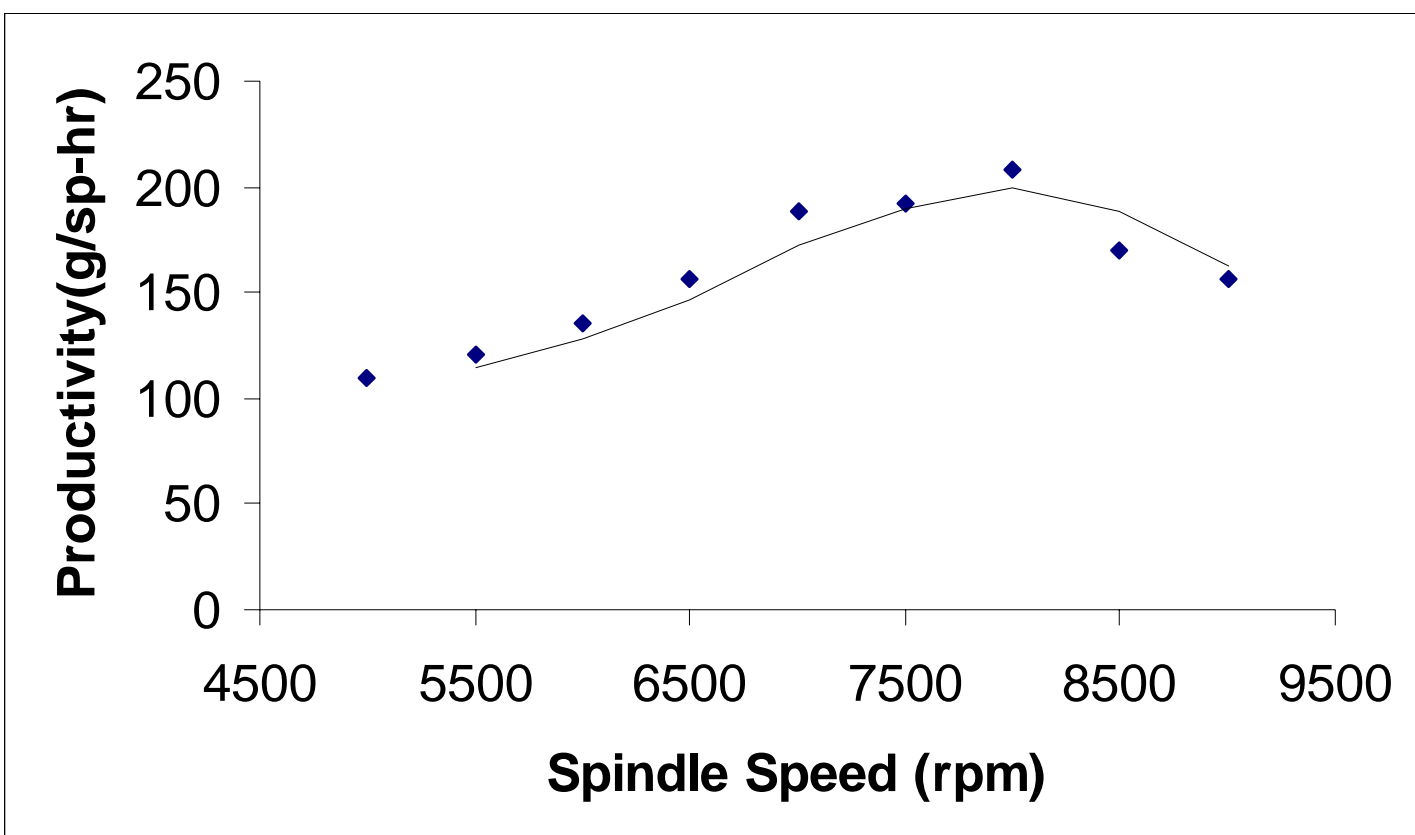

Fig. 3 Spindle speed VS. Productivity of 103 Tex jute yarn 


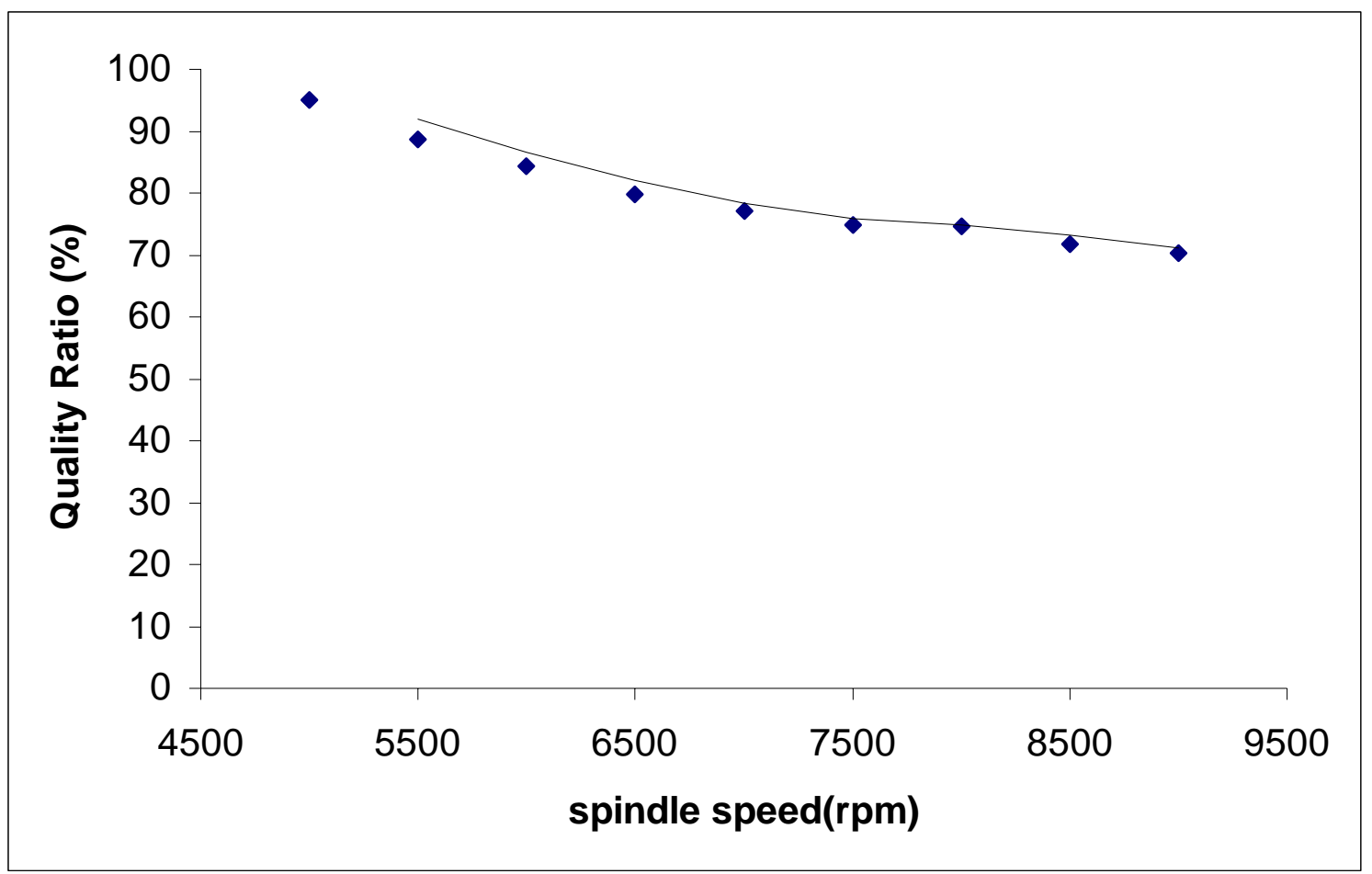

Fig. 4 Spindle speed VS. Quality Ratio of 103 tex jute yarn

The experiment was conducted at the modified apron draft ring spinning machine. The experimental machine is different from the existing flyer spinning machine used in the jute industry as well as the ring spinning machines, commercially available or being used in cotton and textile industry. The modified experimental machine was found capable of producing fine jute yarn of 103 tex. The yarn showed better result at speed of $8000 \mathrm{rpm}$, almost double that of the original flyer type spinning frame of $4250 \mathrm{rpm}$ flyer speed.

\section{Discussion}

Textile properties e.g. strain, tenacity, textile modulus including productivity of the yarn increased with the increase of the spindle speed from 5000 to $8000 \mathrm{rpm}$. They followed a reverse trend when the spindle speed was further increased up to $9000 \mathrm{rpm}$. Although load at break, as well as quality ratio was decreased with the increase of spindle speed. In case of breakage of yarn, initially it increased almost linearly with spindle speed up to 8000 rpm, but it increased abruptly with further increase of the spindle speed up to $9000 \mathrm{rpm}$. The quality ratio of the produced yarn was decreased with the increase of spindle speed due to the loss of insertion of twist at higher spindle speed. In this case, relative speed of traveller is lower although spindle speed is higher which affect the twist of produced yarn [7]. From the quality, productivity and other textile properties shown in the table, $8000 \mathrm{rpm}$ spindle speed seems to be the most suitable speed for production of fine jute yarn of 103 tex in the above mentioned modified spinning frame and productivity of the machine is $208 \mathrm{~g}$ /spyndle-hr.

\section{Conclusion}

Existing apron draft spinning frame can be modified into ring system from its original flyer system. Yarns of 103 tex can be produced at different spindle speeds through the machine. From the textile properties of produced yarns it was shown that spindle speeds has an important effect on properties of yarns and productivity of the machine. From the experiment it was concluded that the quality ratio of produced yarn decreased with the increase of spindle speed and productivity of the machine was optimum at $8000 \mathrm{rpm}$ spindle speed, which was $208 \mathrm{~g} / \mathrm{spindle-hr}$. 


\section{References}

[1] M. O. G. Miazi, “An experimental investigation for optimization of machine parameters in a spinning machine for production of fine jute yarn”. Ph. D. Thesis, BUET, 2002, pp.84,95.

[2] M. O. G. Miazi, “Adaptation of ring spinning in the flyer spinning machine for making fine jute yarn”. M. Sc. Thesis, BUET, 1997, pp.58-60.

[3] R.R Atkinson, "Jute fibre to yarn”, Heywood Books, London, 1964, p 33..

[4] M. A. S Sheikh, "Fine Yarn spinning for Jute". Bangladesh Journal of Jute and Fibre Research, Vol.VII , 1982, p.79.

[5] M. O. G Miazi. “ Development of flyer spinning system by adapting ring spinning system." Bangladesh Journal of Jute and fibre Research, Vol. XXIII , 2000, pp. 61-68.

[6] W.E. Morton \& J.W.S. Hearle, "Physical properties of textile fibre”. The Textile Institute, Manchester, UK. , p.122, 1962.

[7] M.O.G Miazi., L.B. Lutfar \& M.A.R, Sarkar “An experimental investigation for determination of spindle speed of a modified apron draft spinning machine for production of fine jute yarn”. Proceeding of the Int. conf. on Manufacturing, ICM Dhaka. 2002, pp.602-607.

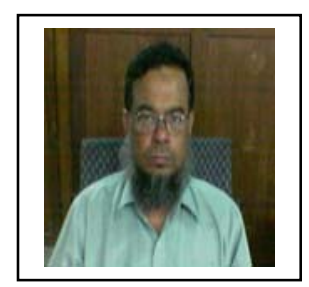

Md. Osman Ghani Miazi is working as the Chief Scientific Officer, Mechanical Processing Division, Bangladesh Jute Research Institute, Manik Mia Avenue, Dhaka-1207.

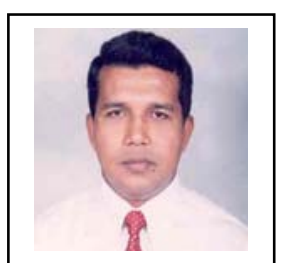

A.K.M. Mahabubuzzaman is working as the Principal Scientific Officer, Department of Spinning, Mechanical Processing Division, Bangladesh Jute Research Institute, Manik Mia Avenue, Dhaka-1207. He received B.Sc. in Textile Technology, MBA and Ph.D. degrees. He obtained Prime Minister's Scholarship for Ph.D. Program. He is engaged in Research and Development activities with natural and allied fibres for more than twelve years in Bangladesh Jute Research Institute. He has thirty national and international scientific papers. He is the Life Member of Institution of Engineers, Dhaka, Bangladesh and the Member of Institution of Textile Engineers and Technologists, and Asiatic society, Dhaka, Bangladesh. $\mathrm{He}$ is the Vice President of Scientist Association, Bangladesh Jute Research Institute. 